\title{
Rescue of Outer Hair Cells with Antisense Oligonucleotides in Usher Mice Is Dependent on Age of Treatment
}

\author{
Abhilash Ponnath, ${ }^{1}$ Frederic F. Depreux, ${ }^{2}$ Francine M. Jodelka, ${ }^{2}$ Frank Rigo, ${ }^{3}$ \\ Hamilton E. Farris, ${ }^{1,4,5}$ Michelle L. Hastings, ${ }^{2}$ and Jennifer J. Lentz ${ }^{1,5}$ \\ ${ }^{1}$ Neuroscience Center of Excellence, Louisiana State University Health Sciences Center, 2020 Gravier Street, 8th Floor, New \\ Orleans, LA 70112, USA \\ ${ }^{2}$ Department of Cell Biology and Anatomy, Chicago Medical School, Rosalind Franklin University of Medicine and Science, \\ 3333 Green Bay Rd, North Chicago, IL 60064, USA \\ ${ }^{3}$ Ionis Pharmaceuticals, 2855 Gazelle Court, Carlsbad, CA 92010, USA \\ ${ }^{4}$ Department of Cell Biology and Anatomy, Louisiana State University Health Sciences Center, 1901 Perdido Street, New \\ Orleans, LA 70112, USA \\ ${ }^{5}$ Department of Otolaryngology and Biocommunications, Louisiana State University Health Sciences Center, 533 Bolivar Street, \\ New Orleans, LA 70112, USA
}

Received: 6 February 2017; Accepted: 4 September 2017; Online publication: 12 October 2017

\begin{abstract}
The absence of functional outer hair cells is a component of several forms of hereditary hearing impairment, including Usher syndrome, the most common cause of concurrent hearing and vision loss. Antisense oligonucleotide (ASO) treatment of mice with the human Usher mutation, Ush1c c.216G $>$ A, corrects gene expression and significantly improves hearing, as measured by auditory-evoked brainstem responses (ABRs), as well as inner and outer hair cell (IHC and OHC) bundle morphology. However, it is not clear whether the improvement in hearing achieved by ASO treatment involves the functional rescue of outer hair cells. Here, we show that Ush1c c.216AA mice lack OHC function as evidenced by the absence of distortion product otoacoustic emissions (DPOAEs) in response to low-, mid-, and highfrequency tone pairs. This OHC deficit is rescued by
\end{abstract}

Electronic supplementary material The online version of this article (https://doi.org/10.1007/s10162-017-0640-x) contains supplementary material, which is available to authorized users.

Correspondence to: Michelle L. Hastings · Department of Cell Biology and Anatomy, Chicago Medical School - Rosalind Franklin University of Medicine and Science 3333 Green Bay Rd, North Chicago, IL 60064, USA. Telephone: (847) 578-8517; email: Michelle.hastings@rosalindfranklin.edu treatment with an ASO that corrects expression of Ush1c c.216G $>$ A. Interestingly, although rescue of inner hairs cells, as measured by ABR, is achieved by ASO treatment as late as 7 days after birth, rescue of outer hair cells, measured by DPOAE, requires treatment before post-natal day 5 . These results suggest that ASO-mediated rescue of both IHC and OHC function is age dependent and that the treatment window is different for the different cell types. The timing of treatment for congenital hearing disorders is of critical importance for the development of drugs such ASO-29 for hearing rescue.

Keywords: Usher syndrome, hearing loss, USH1C, c.216G $>$ A mutation, harmonin, antisense oligonucleotides, outer hair cells, DPOAE, inner hair cells, ABR, splicing, RNA

\section{INTRODUCTION}

Usher syndrome (Usher) is an autosomal recessive disorder characterized by hearing impairment and delayed onset retinitis pigmentosa (RP) that affects 1 in 20,000 individuals worldwide (Keats and Corey 1999). Fifteen genes are associated with three clinical subtypes of Usher. Six genes are known to cause type 1 Usher (USH1) (Mathur and Yang 2015), the most 
severe form with profound sensorineural hearing impairment and vestibular are flexia at birth, and adolescent-onset RP. One form of Usher syndrome results from mutations in USH1C, which encodes Harmonin, a scaffolding protein that localizes to auditory hair cells and is essential for normal hair bundle morphogenesis and mechanotransduction (Verpy et al. 2000; Boeda et al. 2002; Lefevre et al. 2008; Grillet et al. 2009). Some mutations in the USH1C gene cause non-syndromic hearing impairment and others cause USH1 (Bitner-Glindzicz et al. 2000; Verpy et al. 2000). A mutation at position c. $216 \mathrm{G}>\mathrm{A}$ in exon 3 of the USHIC gene creates an aberrant splice site the use of which results in a truncated messenger RNA (mRNA) and Harmonin protein (Lentz et al. 2005) and is responsible for type 1C Usher (USH1C) in the Acadian population of Louisiana, USA and Canada. Similar to USH1C human patients, Ush1c c.216G $>$ A knock-in mice (216AA) exhibit auditory, vestibular, and visual deficits. These Usher mice have little or no auditory evoked brainstem responses, exhibit circling behavior, and show abnormal electroretinograms (ERG) (Lentz et al. 2007). In the cochlea, peripheral defects in hair cell bundle morphology, as well as missing inner and outer hair cells, are present in 216AA mutant mice (Lentz et al. 2010; Lentz et al. 2013).

We have previously reported on a splice switching antisense oligonucleotide (ASO) (termed ASO-29) that base pairs to the $216 \mathrm{~A}$ region and thereby blocks the recognition of the aberrant splice site. Remarkably, a single systemic dose of this ASO targeting the 216A mutation, administered a few days after birth, improves these peripheral defects and rescues hearing and circling behavior in 216AA mice (Lentz et al. 2013). A significant decrease in auditory-evoked brainstem response (ABR) thresholds was measured for several months after ASO treatment, indicative of the rescue of IHC function and hearing. Here, we investigate whether rescue of OHC function contributes to the hearing rescue by ASOs in Usher mice.

OHC function is commonly assessed by the measurement of otoacoustic emissions (OAEs) (Gold 1948; Kemp 1978, 1979), which are sounds produced by the inner ear in response to acoustic stimuli. The emissions are the result of the active process of OHCs to amplify the passive motion of the basilar membrane created by sound waves (Horner et al. 1985; Schrott et al. 1991; Dallos et al. 2008). When stimulated, OHCs elongate and shorten via the membrane protein prestin, amplifying basilar membrane displacement (Zheng et al. 2000; Liberman et al. 2002) and sharpening frequency discrimination. Conversely, the loss of OHCs results in a 50-dB threshold rise in audiograms with a loss of frequency selectivity in gerbils, chinchillas, macaque, and patas monkeys (Stebbins et al. 1969; Clark et al. 1974; Ryan and Dallos 1975; Moody et al. 1978; Stebbins et al. 1979; Smith et al. 1987).

Distortion product otoacoustic emissions (DPOAEs) are generated by the non-linear interaction of two tones at specific regions along the basilar membrane and reflect the function of the active process of OHCs. Here, we show that DPOAEs are absent in Usher mice but can be recovered by treatment with ASOs at post-natal day 1 (P1), an effect that is accompanied by a significant reduction in ABR thresholds, indicating a rescue of hearing. Treatment at P5 does not result in measureable DPOAEs, though significant reductions in ABR thresholds are detected, albeit not as reduced as with an earlier treatment time. Multiple administrations of ASOs beginning at P1 lead to more robust recovery of DPOAE and ABR responses. These results indicate that ASO-29 treatment can rescue IHC and OHC function and recovery is dependent on the timing of treatment, suggesting a developmental window during which expression of Ush $1 c$ and harmonin protein production is essential.

\section{METHODS}

Mice

Ush1c c.216G $>$ A knock-in (216AA) and littermate mice were bred and treated at LSUHSC. All procedures met the NIH guidelines for care and use of laboratory animals and were approved by the Animal Care and Use Committee at LSUHSC. Mice were genotyped as described previously (Lentz et al. 2010).

\section{ASOs}

Antisense oligonucleotides (2'-O-methoxyethyl-modified, Ionis Pharmaceuticals, Inc.) targeting the Ush $1 c$ c. 216G $>$ A mutation (ASO-29) (5'-AGCT GATCATATTCTACC- $3^{\prime}$ ) and a non-specific control (ASO-C) (5'-TTAGTTTAATCACGCTCG-3') were generated as previously described by (Lentz et al. 2013).

\section{Intraperitoneal Injection}

Ush1c 216AA mutant and control 216GA mice were treated systemically by intraperitoneal injection with $300 \mathrm{mg} / \mathrm{kg}$ body weight of ASOs. For a single treatment regimen, mice were given one dose in the first week of life on post-natal day 1, 5, or 7. For a multiple treatment regimen, mice were given two doses in the first week of life on post-natal days 1 and $3(\mathrm{P} 1,3)$ or four doses on post-natal days $1,3,5$, and 7 $(\mathrm{P} 1,3,5,7)$. 


\section{Distortion Product Otoacoustic Emission Analysis}

Distortion product otoacoustic emissions were measured to evaluate outer hair cell function in 216AA mice and controls at 1 month (P33-36), 3 months, and 6 months of age. Mice were anesthetized (intraperitoneal ketamine/xylazine, $100 / 6 \mathrm{mg} / \mathrm{kg}$ body weight, respectively), and body temperature was maintained near $38{ }^{\circ} \mathrm{C}$ with a heat pad. Primary tones $\mathrm{f} 1$ and $\mathrm{f} 2$ were selected to stimulate the low and mid-frequency regions of mouse auditory sensitivity. Primary tones (6363, 6672, 10,008, 13,342, 16,000 , and $24,500 \mathrm{~Hz}$ ) were presented at equal amplitude, with the ratio of $\mathrm{f} 2$ and $\mathrm{f} 1$ (f2/f1) equal to 1.199 (Harris et al. 1989; Martin et al. 2006). Stimulus amplitude was calibrated $( \pm 1.5 \mathrm{~dB})$ at the position of tympanum using continuous tones with a Bruel and Kjaer 2610 measuring amplifier (fast, linear weighting), 4135 microphone (grid on), and a 4230 pistonphone calibrator. Equal amplitudes of the two tone stimuli (f1 and f2) were checked with a dynamic signal analyzer (Hewlett Packard, 35106A); overall amplitude was controlled with TDT PA2 programmable attenuators and allowed to mix in the ear canal. The range of amplitudes tested was 35 to $75 \mathrm{~dB}$ sound pressure level (SPL) (re. $20 \mu \mathrm{Pa}$ ). Tones were generated (195 kHz srate; $168 \mathrm{~ms}$ pulses with $0.5 \mathrm{~ms}$ linear ramps) using custom software and two EC1 (TDT) electrostatic speakers driven by ED1 electrostatic speaker driver. The stimuli were delivered to the left ear canal with an acoustic probe assembly (Entymotic Research, ER-10B+), tightly coupled to the ear. The ER-10B+ Low Noise Microphone System, also in the left ear canal, was used to detect the emission signal. The emission was digitized in $210 \mathrm{~ms}$ duration sweeps (7 $\mathrm{\mu s}$; sampling period; 50 repetitions) and amplified (20 dB) using a TDT and System I array processor. Custom built MATLAB R2013a programs were used to compute the power of the emission signal using fast Fourier Transform (sampling frequency of $0.5 \mathrm{~Hz}$ ) at respective 2f1-f2 frequencies. The noise floor was measured as the average power $100 \mathrm{~Hz}$ above and below the 2f1-f2 frequency. Thus, the DPOAE signal to noise ratio (SNR) is the amplitude at the 2f1-f2 frequency/noise floor. For plotting DPOAE thresholds, iso-response curves show the minimum $\mathrm{f} 1$ and $\mathrm{f} 2$ amplitude necessary to elicit a DPOAE (2f1-f2) with amplitude of $3 \mathrm{~dB}$ relative to the noise floor. Thus, elevated DPOAE thresholds reflect the case in which the noise floor has remained the same, but more stimulus power is required to produce the distortion product, reflecting reduced function of the active process. All experiments were conducted in a sound proof chamber. The signal-to-noise ratios were obtained for each of the pairs of tones tested. Data are reported as standard error of the mean.

\section{Auditory-Evoked Brain Stem Response Analysis}

Hearing function was assessed as described by Lentz et al. (2013). Briefly, auditory-evoked brainstem responses (ABR) were used to evaluate hearing thresholds in Ush1c 216AA mutant and control mice at 1 month (P33-36), 3 months, and 6 months of age. Mice were anesthetized (intraperitoneal ketamine/ xylazine, $100 / 6 \mathrm{mg} / \mathrm{kg}$ body weight, respectively), and body temperature was maintained near $38{ }^{\circ} \mathrm{C}$ with a heat pad. All acoustic stimuli were $5 \mathrm{~ms}$ pulses with $0.5 \mathrm{~ms}$ linear ramps. Tonal stimuli consisted of 8,16 , and $32 \mathrm{kHz}$ to stimulate the low-, mid-, and highfrequency regions of basilar membrane. A broadband noise $(\mathrm{BBN})$ was used to stimulate the whole cochlea. After amplification (Cambridge Audio Azur 540a Integrated amplifier), the stimuli were broadcast through a Motorola piezoelectric speaker (model no. 15D87141E02) fitted with a plastic funnel and $2 \mathrm{~mm}$ diameter tubing over the speaker front, producing an acoustic wave guide positioned in the external meatus approximately $0.5 \mathrm{~cm}$ from the tympanum. Using continuous tones, stimulus amplitude was calibrated at the end of the tubing with a Bruel and Kjaer 2610 measuring amplifier (fast, linear weighting), 4135 microphone (grid on), and 4230 pistonphone calibrator. All stimulus amplitudes were in $\mathrm{dB}$ SPL (re. $20 \mu \mathrm{Pa}$ ). Stimuli were generated (195 kHz srate) and responses digitized (10 kHz srate) using TDT System III hardware and software (BioSig). ABRs were recorded with a 27 gauge subdermal steel electrode (Ambu Neuroline Subdermal) placed behind the left ear, with indifferent and ground electrodes (steel wire, 30 gauge) placed subcutaneously at the vertex and hind limbs, respectively. After amplification (60 dB, Grass P511 AC), filtering $(0.3 \mathrm{~Hz}-1 \mathrm{kHz}$; TDT PF1), and averaging ( $n=600-1024)$, thresholds $( \pm 6 \mathrm{~dB})$ were determined by visual inspection as the minimum stimulus amplitude that produced an ABR wave pattern similar to that produced for the highest intensity stimulus $(90 \mathrm{~dB})$. Data are reported as standard error of the mean.

We note that the ABR thresholds reported here are lower than those reported by Lentz et al. (2013). Although the source of this improvement is unclear, there was a difference in how mice were handled in this study compared to those in the previous one. In Lentz et al. (2013), mice were treated with the same dose $(300 \mathrm{mg} / \mathrm{kg})$ at P5 and subsequently shipped via air transport from Chicago to New Orleans where $\mathrm{ABR}$ analysis was performed. We hypothesize that eliminating this environmental stress could explain 
the more effective rescue measured here in locally housed and treated mice. Consistent with this hypothesis, we find that the normal (non-mutant) littermate controls that were shipped as part of the previous study also showed increased ABR thresholds compared to the data here.

\section{RNA Analysis}

Inner ears were isolated and cochleae immediately frozen in liquid nitrogen or stored in Trizol reagent (Life Technologies). RNA was isolated from cochleae using Trizol reagent and analyzed by radioactive RTPCR using primers musUSH1Cex2F ( $5^{\prime}$ CTCATTGA AAATGACGCAGAGAAGG $\left.3^{\prime}\right)$ and musUSH1Cex5R ( $5^{\prime}$ TCTCACTTTGATGGACACGGTCTT $3^{\prime}$ ) to amplify the correctly spliced (450 nt amplicon) or cryptic spliced (415 nt amplicon) Ush1c transcripts as previously described (Lentz et al. 2013). Briefly, $1 \mu \mathrm{g}$ of RNA was reverse transcribed using GoScript Reverse Transcriptase (Promega, Fitchburg, WI) and $1 \mu \mathrm{g}$ of cDNA was used in PCR reactions with GoTaq Green (Promega) supplemented with primers and $\alpha^{32} \mathrm{P}-\mathrm{dCTP}$. Products were separated on a $6 \%$ non-denaturing polyacrylamide gel and quantitated using a Typhoon 9400 phosphorimager (GE Healthcare). Data are reported as standard error of the mean. Statistical calculations were performed using Prism 6 version $6.0 \mathrm{~h}$. The list of statistical comparisons and analyses can be found in Supplemental Table Comparison 5.

\section{Immunohistochemistry}

Fluorescent labeling of microdissected preparations of the organ of Corti was used to study the localization of ASOs in mutant and heterozygote mice treated with ASOs or vehicle (saline) as described by Lentz et al. (2013). Briefly, a small opening was made in the apex of isolated cochleae and perfused with $2 \%$ paraformaldehyde in $0.1 \mathrm{M}$ phosphate buffer, $\mathrm{pH} 7.4$ through the round and oval windows. The cochleae were post-fixed for $2 \mathrm{~h}$ at $4{ }^{\circ} \mathrm{C}$ with gentle rocking followed an overnight wash at $4{ }^{\circ} \mathrm{C}$ with PBS. The organs of Corti were then microdissected away from the cochlear bone, tectorial membrane removed with a fine forceps, and the stria vascularis trimmed. All incubations were performed with gentle rocking. Blocking and washing incubations were performed at room temperature and antibody incubations were performed at $4{ }^{\circ} \mathrm{C}$. Tissues were immersed in Image IT (I36933, Thermo Fisher Scientific) for $30 \mathrm{~min}$ and then blocked for $2 \mathrm{~h}$ with $10 \%$ normal donkey serum, $0.5 \%$ bovine serum albumin, $0.03 \%$ saponin, and $0.1 \%$ Triton X-100 in PBS. Primary and secondary incubations were performed each for $2 \mathrm{~h}$ with $3 \%$ normal donkey serum, $0.5 \%$ bovine serum albumin,
$0.03 \%$ saponin, and $0.1 \%$ Triton X-100 in PBS. To analyze ASO localization in cochlear hair cells, polyclonal rabbit anti-ASO antibodies (1:500; Ionis Pharmaceuticals) and mouse monoclonal antiparvalbumin antibodies (1:250; P3088, Sigma-Aldrich) were used. Tissues were washed three times for $15 \mathrm{~min}$ each in $0.1 \%$ Tween-20 in PBS after primary and secondary antibodies: donkey anti-rabbit Alexa555 (1:250; A31572, Thermo Fisher Scientific) and donkey anti-mouse Alexa488 (1:250; R37114, Thermo Fisher Scientific) incubations. Nuclei were counterstained with DAPI ( $1 \mu \mathrm{g} / \mathrm{ml}$; D9542, Sigma-Aldrich). All labeled specimens were mounted and stored in Prolong Gold (Thermo Fisher Scientific). Imaging was performed with a Zeiss motorized system operated with LSM software (Zeiss) and equipped with 405-, 543-, and 633-nm diodes along with a multiline argon laser $(457,488$, and $515 \mathrm{~nm}$ ) and several objectives that include the Plan-Apochromat $40 \times(\mathrm{NA}=1.4$ oil $)$ and Plan-Apochromat $63 \times(\mathrm{NA}=1.4$ oil $)$. Planes were captured at a resolution of $2048 \times 2048$ pixels and speeds of 1-2 $\mu$ s per pixel. Z-stack images were reconstructed and analyzed using ImageJ, Fuji, and Photoshop software.

\section{Statistical Analysis}

ABR threshold, DPOAE thresholds, and DPOAE SNRs were analyzed in separate one-way analysis of variance models (ANOVA). Threshold or SNR was the outcome variable and gene, dose, stimulus intensity, and treatment were combined into a one-way set of combinations of predictive factors at each time point to deal with imbalances in the number of observations. ANOVA analysis was followed with a TukeyKramer adjustment for multiple comparisons which has good performance with unequal numbers of replicates (Kramer 1956). The reported $P$ values are from alpha level adjusted $t$ tests of differences between least-square means (Milliken and Johnson 1984). Differences were considered statistically significant when $P \leq 0.05$. Statistical calculations were performed using Statistical Analysis System 9.4 software (SAS Institute Inc.). The list of statistical comparisons and analyses associated with ABRs and DPOAEs can be found in the Supplemental Table.

\section{RESULTS}

\section{$U$ sh $1 c^{216 A A}$ Mice Lack Outer Hair Cell Function}

To test the function of the outer hair cells in the Ush1c ${ }^{216 \mathrm{AA}}$ mice (216AA), DPOAEs were measured at 1 month of age and compared to heterozygous Ush1c ${ }^{216 G A}$ (216GA) mice. The power spectrum of the recorded otoacoustic emissions in response to 
tone pairs ( $\mathrm{f} 1$ and $\mathrm{f} 2$ ) demonstrated that 216GA mice produce distortion products at 2f1-f2 and other harmonics (Fig. 1a, c). 216GA mice showed a strong signal at 2f1-f2 for the tone pairs in the low (6363, 7630 and $6672,8000.5 \mathrm{~Hz})$, mid $(10,008,12,001$ and $13,342.5,15,999 \mathrm{~Hz})$, and high $(16,000,19,186$ and 24,500, 29,378.5 Hz) frequencies. In contrast, 216AA mice had minimal or no distortion products (Fig. 1b). The 2f1-f2 distortion product at all of the tone pairs tested in 216AA mutant mice was significantly lower at a sound intensity of $75 \mathrm{~dB}$ SPL compared with 216GA mice (Fig. 1d, f). These results indicate that 216AA mice have a profound absence of OHC function.

\section{Age-Dependent Rescue of DPOAEs in ASO- Treated Ush $1 c^{216 A A}$ Mice}

To test whether ASO treatment can rescue OHC function in Ush1c ${ }^{216 \mathrm{AA}}$ mice, 216AA mice were treated with ASO-29 by intraperitoneal injection in the first week of life. Because OHC development continues post-natally, we injected the ASO at different times after birth to assess the requirement for treatment, and hence harmonin protein, during the development of OHCs. Dosing of mice with two or four injections of ASO every other day was also tested to maximize ASO delivery to cochlear hair cells. 216AA mice that had received a single ASO treatment at post-natal day 1 (P1) and multiple treatments at P1 and $3(\mathrm{P} 1,3)$ or at $\mathrm{P} 1,3,5$, and $7(\mathrm{P} 1,3,5,7)$ had significantly increased 2f1-f2 distortion products at 1 month of age at a sound intensity of $75 \mathrm{~dB}$ SPL for all tone pairs compared with untreated 216AA mice (Fig. 1e, f). A single ASO treatment given at P5, however, did not increase 2f1-f2 distortion products, suggesting that rescue of $\mathrm{OHC}$ function requires treatment before P5 either due to a requirement for harmonin expression before P5 or because less ASO reaches the hair cells when pups are treated with ASO at P5.

In order to test the stability of the effect of ASO-29 treatment on OHC function, DPOAEs were measured at 1,3 , and 6 months after treatment. The DPOAE signal to noise ratio (SNR) at 2f1-f2 for the 216GA control mice at 1,3 , and 6 months of age increased with increasing intensity levels (Figs. 2 and 3). By comparison, the SNRs for untreated 216AA mutant mice relative to those in 216GA littermates were low at all intensities and frequencies at all ages tested. However, a single ASO treatment at P1 (Fig. 2) and multiple ASO treatments at P1, 3 and P1, 3, 5, 7 (Fig. 3) significantly increased 2fl-f2 SNRs with increasing stimulus intensity levels. For these treatments, responses to stimulus intensities were significantly elevated at 1 month of age for all frequencies except $8015 \mathrm{~Hz}$ in mice treated at P1 (Fig. 2a) and 12,814 and 19,621 Hz in mice treated at P1,3,5,7 (Fig. 3a). There was no difference in SNRs at 1 month of age between single and multiple ASO treatments at P1 and P1, 3, except at $8015 \mathrm{~Hz}$, in which $\mathrm{P} 1,3$ treatments resulted in a significant increase in SNR (75 dB SPL; Supplemental Table Comparison 1). There was, however, a significant difference in SNRs at all frequencies except for the frequency pair at $19621 \mathrm{~Hz}$ between two $(\mathrm{P} 1,3)$ and four doses $(\mathrm{P} 1,3,5,7)$ of ASO with the largest increase in SNR observed in mice treated at P1, 3. At 1 month of age, a single ASO treatment in 216AA mice at P5 resulted in no change in DPOAE 2f1-f2 SNRs at all intensities at all frequencies relative to untreated 216AA mice (Figs. 1d and $2 \mathrm{a})$.

At 3 months of age, the significant increase in SNR was sustained at $8015 \mathrm{~Hz}$ for 216AA mice treated with ASOs at P1 (Fig. 2b) and at multiple low-midfrequency pairs for those treated at P1, 3 (Fig. 3b). Interestingly, a single dose of ASO-29 at P1 was the only treatment regimen that had a sustained significant increase in SNRs at low-mid frequencies at 6 months of age (Figs. 2c and 3c).

At 1, 3, and 6 months of age, DPOAE thresholds at all frequency pairs tested were significantly elevated in 216AA mutant mice compared with 216GA normal controls (Fig. 4). Treatment of 216AA mice with one dose at P1 or two doses (at P1 and 3) of ASO-29 resulted in significantly lower DPOAE thresholds at 1 month of age at low ( $\mathrm{fl} / \mathrm{f2}=6.672 / 8 \mathrm{kHz}$ tone pair). Treatment at P1, 3 also resulted in a significantly lower DPOAE threshold at 1 month of age at mid frequencies (f1/ $\mathrm{f} 2=10 / 12$ and $13.342 / 16 \mathrm{kHz}$ tone pairs), whereas four doses (at P1, 3, 5, and 7) resulted in a significantly lower DPOAE threshold at 1 month of age at low frequency $(\mathrm{fl} / \mathrm{f2}=6.363 / 7.63 \mathrm{kHz})$ compared to mutant controls (Fig. 4a). The reduction in DPOAE thresholds at all frequencies in ASO-treated 216AA mice, however, was not sustained at 3 and 6 months of age, with the exception of a significantly lower DPOAE threshold at low frequency $(\mathrm{fl} / \mathrm{f2}=6.363 / 7.63 \mathrm{kHz})$ in 6 -month-old 216AA mice treated once at P1 (Fig. 4b, c). This finding supports our results from DPOAE SNR measurements that show no significant effects at amplitudes below $70 \mathrm{~dB}$ across frequencies (Figs. 2 and 3). 216AA mutant mice treated at $\mathrm{P} 5$ had little or no distortion products and were similar to untreated 216AA mutant mice (Fig. 4b, c). Taken together, these data demonstrate that initiation of ASO treatment prior to $\mathrm{P} 5$ is required for rescue of the 2f1-f2 distortion product and multiple treatments may provide some additional early benefits, which are not sustained at later points of treatment.

Age-Dependent Improvement in ABR Thresholds in ASO-treated Ush1 $c^{216 A A}$ Mice

To measure the effect of the different ASO-29 treatment regimens on hearing rescue, ABR analysis 

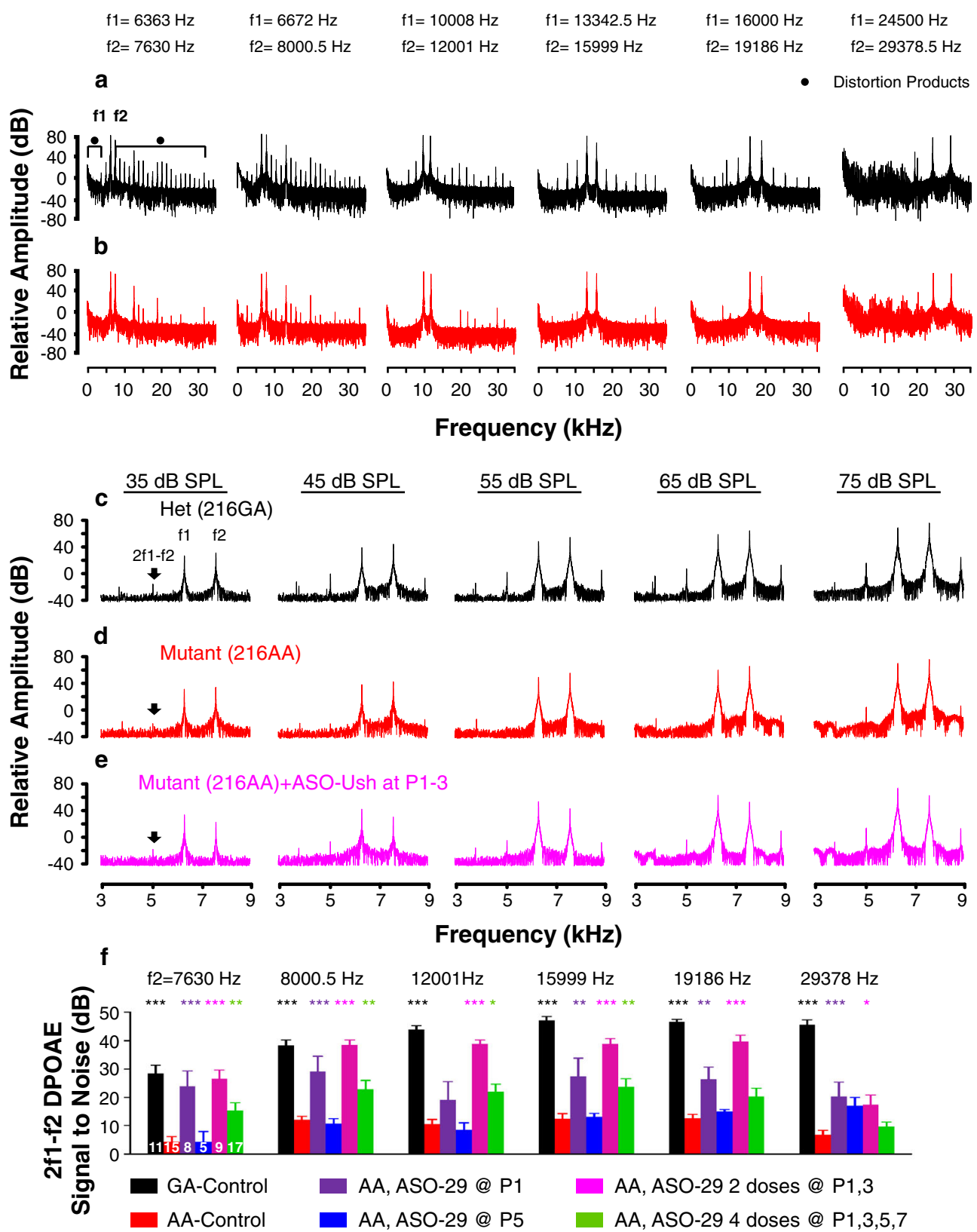

Fig. 1. Distortion product optoacoustic emission analysis in ASOtreated Ush1c mice. Representative power spectra for all tone pairs at the highest stimulus intensity of $75 \mathrm{~dB}$ SPL from a a $216 \mathrm{GA}$ control littermate (black) and b Ush1c 216AA mouse (red). Power spectrum of the tone pairs at primary frequency tones of 6363 and $7630 \mathrm{~Hz}$ for Ush1c 216AA mice treated with $300 \mathrm{mg} / \mathrm{kg}$ of ASO-29 at P1-3 (e, pink line) and untreated 216AA (d, red line) and 216GA control (c, black line) mice at 1 month of age. The primary tones $\mathrm{f} 1$ and $\mathrm{f} 2$ and 2f1-f2 distortion product (black arrow) peaks are indicated. Response at 2f1-f2 increases with stimulus intensity for 216GA mice and 216AA mice treated with ASOs at P1-3 but not for untreated 216AA mice. f Average 2f1-f2 distortion product at

was performed at 1,3 , and 6 months of age on 216AA mutant mice treated with single or multiple doses of the ASO at different times in the first week of life, as described above. ABR thresholds of untreated or
$75 \mathrm{~dB}$ SPL for the tone pairs in 216AA mice treated with $300 \mathrm{mg} / \mathrm{kg}$ of ASO-29 with one dose at P1 (purple) or P5 (blue), two doses at $\mathrm{P} 1$ and 3 (P1, 3; pink), or four doses at P1, 3, 5, and 7 (P1, 3, 5, 7; green); 216AA untreated (red) and control littermates (black). The number of mice assayed is indicated in bars. Error bars represent SEM. For each frequency, asterisks indicate significant difference $\left({ }^{*} P \leq 0.05,{ }^{* *} P \leq 0.01,{ }^{* * *} P \leq 0.001\right.$, ANOVA with Tukey-Kramer post-test) from control mutant thresholds (red). $P$ values, specific test, test value, and degrees of freedom for all comparisons in this dataset are shown in Supplemental Table Comparison 1. dB, decibel; SPL, sound pressure level, kHz, kilohertz; Het, heterozygote; $f$, frequency

control-treated 216AA mice were significantly elevated at 1,3, and 6 months of age for all frequencies tested (Lentz et al. 2010, 2013; Figs. 5 and 6). Single and multiple ASO treatments in the first week of life in 


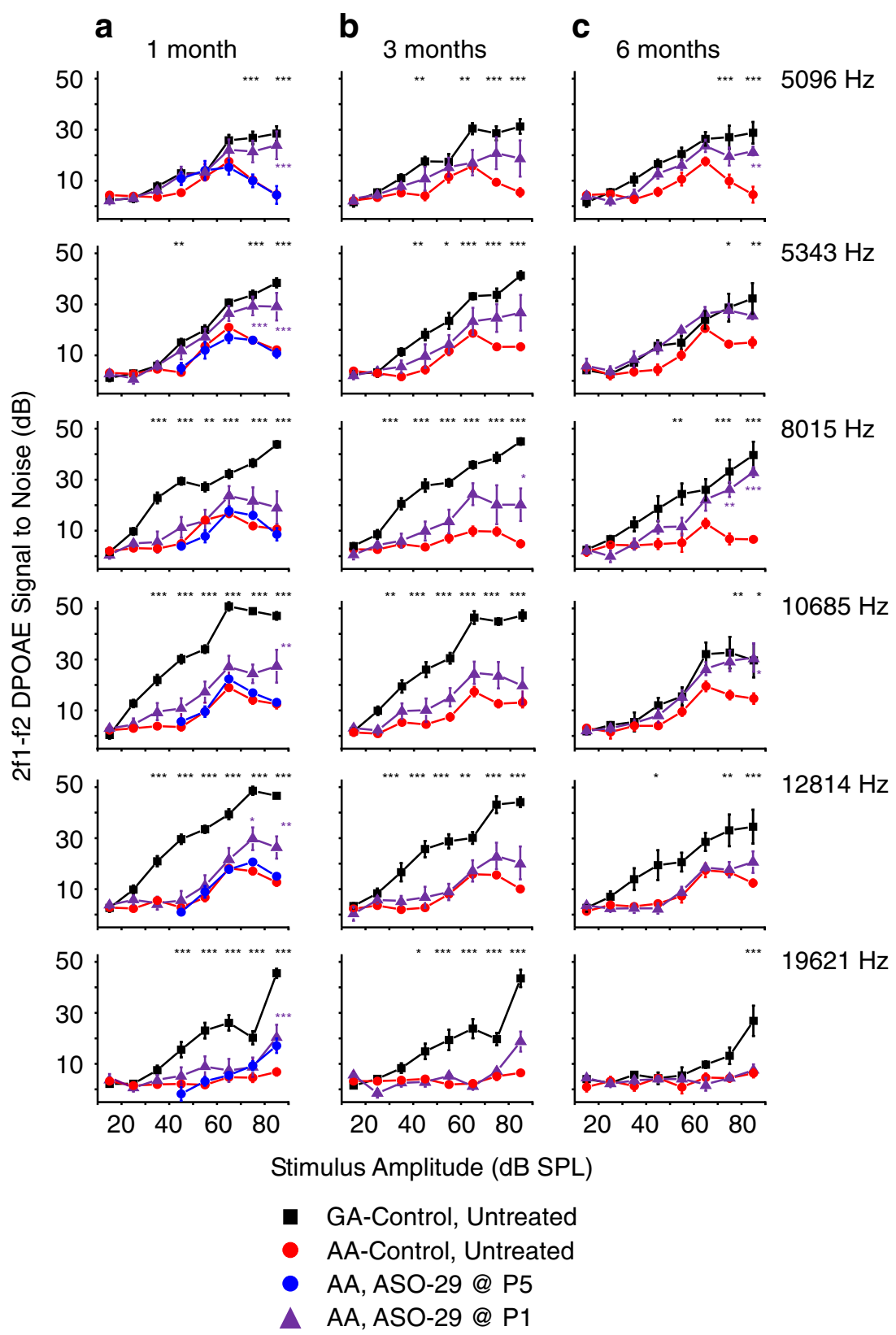

Fig. 2. Analysis of DPOAE signal to noise ratios in Ush1c mice treated with a single dose of ASOs. Signal to noise ratio (SNR) plots at the primary tone pairs tested at 1 month (a), 3 months (b), and 6 months (c) of age for Ush1c 216AA mice treated with $300 \mathrm{mg} / \mathrm{kg}$ of ASO-29 one time at P1 (purple line, $n=8,6$, and 6 at 1, 3, and 6 months of age, respectively) or P5 (blue line, $n=5$ ) and untreated 216AA (red line, $n=15,12$, and 7 at 1,3 , and 6 months of age, respectively) and untreated 216GA (black line, $n=11,11$, and 8 at 1,3 , and 6 months of age, respectively) control mice. Frequency tone pairs: $\mathrm{f} 1=6363 \mathrm{~Hz}, \mathrm{f} 2=7630 \mathrm{~Hz}(2 \mathrm{f} 1-\mathrm{f} 2=5096 \mathrm{~Hz})$; $\mathrm{f} 1=6672 \mathrm{~Hz}, \mathrm{f} 2=8000.5 \mathrm{~Hz}(2 \mathrm{f} 1-\mathrm{f} 2=5243 \mathrm{~Hz}) ; \mathrm{f} 1=10,008 \mathrm{~Hz}$, $\mathrm{f} 2=12,001 \mathrm{~Hz}(2 \mathrm{f} 1-\mathrm{f} 2 \mathrm{DP}$ at $8015 \mathrm{~Hz}) ; \mathrm{f} 1=13,342.5 \mathrm{~Hz}$,

216AA mice rescued ABR thresholds, with earlier intervention and multiple treatments resulting in the lowest thresholds (Figs. 5 and 6). $\mathrm{f} 2=15,999 \mathrm{~Hz}(2 \mathrm{f} 1-\mathrm{f} 2 \mathrm{DP}$ at $10685 \mathrm{~Hz}) ; \mathrm{f} 1=16,000 \mathrm{~Hz}$, $\mathrm{f} 2=19,186 \mathrm{~Hz}(2 \mathrm{f} 1-\mathrm{f} 2 \mathrm{DP}$ at $12814 \mathrm{~Hz}) ; \mathrm{f} 1=24,500 \mathrm{~Hz}$, $\mathrm{f} 2=29,378.5 \mathrm{~Hz}(2 \mathrm{f1}-\mathrm{f} 2 \mathrm{DP}$ at 19621). SNRs are increased at some frequencies at all ages tested with a single ASO treatment at P1, but not P5. Error bars represent SEM. For each frequency, asterisks indicate significant difference $\left(* P \leq 0.05,{ }^{* *} P \leq 0.01,{ }^{* * *} P \leq 0.001\right.$, ANOVA with Tukey-Kramer post-test) from control mutant thresholds (red). $P$ values, specific test, test value, and degrees of freedom for all comparisons in this dataset are shown in Supplemental Table Comparison 1. f, frequency; DP, distortion product; DPOAE, distortion product otoacoustic emission; $\mathrm{Hz}$, Hertz; dB, decibel; SPL, sound pressure level; Het, heterozygote
At 1 month of age, ABR thresholds were significantly reduced in 216AA mice for all ASO treatments at low $(8 \mathrm{kHz})$ and $\operatorname{mid}(16 \mathrm{kHz})$ frequency pure tones 


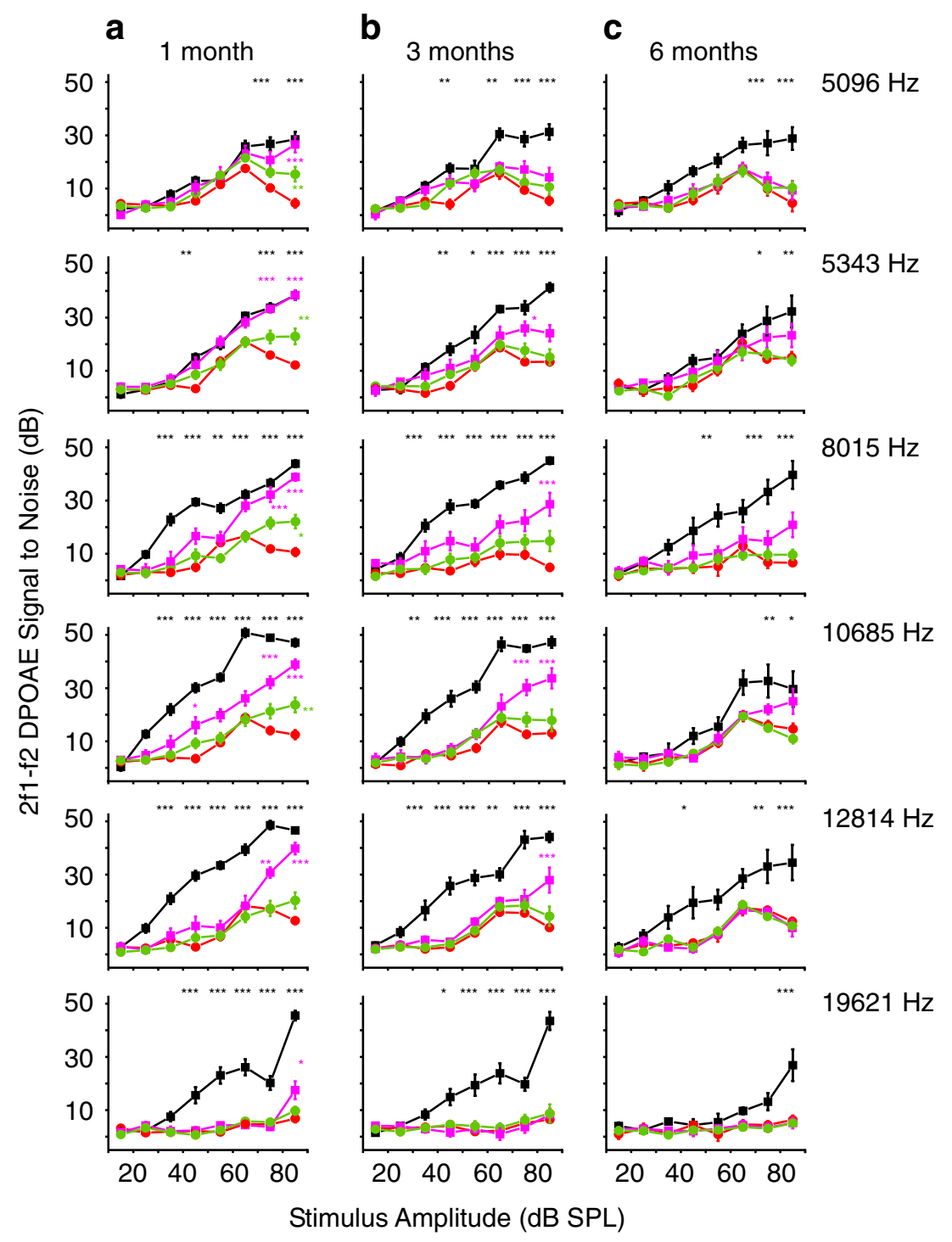

- GA-Control, Untreated

- AA-Control, Untreated

- AA, ASO-29 2 doses @ P1,3

- AA, ASO-29 4 doses @ P1,3,5,7

Fig. 3. Analysis of DPOAE signal to noise ratios in Ush1c mice treated with multiple doses of ASOs. Signal to noise ratio (SNR) plots at the primary tone pairs tested at 1 month (a), 3 months (b), and 6 months (c) of age for Ush1c 216AA mice treated with $300 \mathrm{mg} / \mathrm{kg}$ of ASO-29 twice at P1 and 3 (P1, 3, pink line, $n=9,8$, and 7 at 1, 3, and 6 months of age, respectively) or four times at P1,3, 5, and 7 (P1, 3, 5, 7, green line, $n=17,13$, and 12 at 1,3 , and 6 months of age, respectively) and untreated 216AA (red line, $n=15,12$, and 7 at 1, 3, and 6 months of age, respectively) and 216GA (black line, $\mathrm{n}=11,11$ and 8 at 1,3 and 6 months of age, respectively) control mice. Frequency tone pairs: $\mathrm{f} 1=6363 \mathrm{~Hz}, \mathrm{f} 2=7630 \mathrm{~Hz}(2 \mathrm{f} 1$ $\mathrm{f} 2=5096 \mathrm{~Hz}) ; \mathrm{f} 1=6672 \mathrm{~Hz}, \mathrm{f} 2=8000.5 \mathrm{~Hz}(2 \mathrm{f} 1-\mathrm{f} 2=5243 \mathrm{~Hz})$; $\mathrm{f} 1=10,008 \mathrm{~Hz}, \mathrm{f} 2=12,001 \mathrm{~Hz}(2 \mathrm{f} 1-\mathrm{f} 2 \mathrm{DP}$ at $8015 \mathrm{~Hz})$; $\mathrm{f} 1=13,342.5 \mathrm{~Hz}, \mathrm{f} 2=15,999 \mathrm{~Hz}(2 \mathrm{f} 1-\mathrm{f} 2 \mathrm{DP}$ at $10685 \mathrm{~Hz})$; $\mathrm{f} 1=16,000 \mathrm{~Hz}, \mathrm{f} 2=19,186 \mathrm{~Hz}(2 \mathrm{f} 1-\mathrm{f} 2 \mathrm{DP}$ at $12814 \mathrm{~Hz})$; $\mathrm{f} 1=24,500 \mathrm{~Hz}, \mathrm{f} 2=29,378.5 \mathrm{~Hz}(2 \mathrm{f} 1-\mathrm{f} 2 \mathrm{DP}$ at 19621). SNRs are increased at some frequencies at 1 and 3 months of age with multiple ASO treatments in the first week of life. The number of treatments (doses) is indicated. Error bars represent SEM. For each frequency, asterisks indicate significant difference $\left({ }^{*} P \leq 0.05\right.$, ${ }^{* *} P \leq 0.01,{ }^{* * *} P \leq 0.001$, ANOVA with Tukey-Kramer post-test) from control mutant thresholds (red). $P$ values, specific test, test value, and degrees of freedom for all comparisons in this dataset are shown in Supplemental Table Comparison 1. f, frequency; DP, distortion product; DPOAE, distortion product otoacoustic emission; $\mathrm{Hz}$, Hertz; dB, decibel; SPL, sound pressure level; Het, heterozygote and broadband noise (BBN) stimuli when compared with control-treated 216AA mice (Figs. 5a and 6a).
Furthermore, the ABR thresholds of P1- and P1, 3treated 216AA mice were not significantly different at 


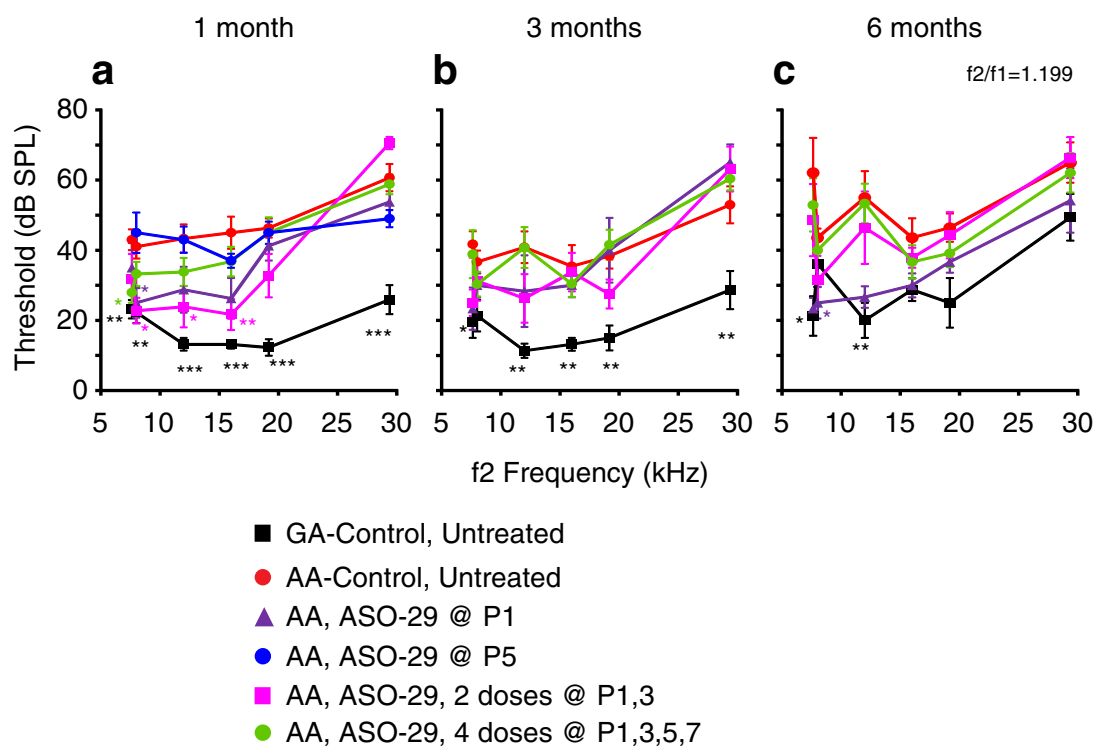

Fig. 4. Distortion product otoacoustic emissions analysis in Ush1c mice treated with ASOs. Average DPOAE thresholds (dB SPL) at 1 month (a), 3 months (b), and 6 months (c) of age to tone pairs ranging from 6363 to $29,378.5 \mathrm{kHz}$ from $216 \mathrm{AA}$ mice treated with $300 \mathrm{mg} / \mathrm{kg}$ of ASO-29 one time at P1 (purple line, $n=8,6$, and 6 at 1,3 , and 6 months of age, respectively) or P5 (blue line, $n=5$ ) or multiple times at P1-3 (pink line, $n=9,8$, and 7 at 1,3 , and 6 months, respectively) or P1-7 (green line, $n=17,13,12$ at 1,3 and 6 months of age, respectively); 216AA mice treated with ASO-C or untreated (red line, $\mathrm{n}=15,12,7$ at 1,3 and 6 months of age, respectively); and 216 untreated GA mice (black line, $n=11,11,8$ at
1,3 , and 6 months of age, respectively). DPOAE thresholds are reduced with some ASO treatments in 216AA mice. Total number of treatments (doses) is indicated. Error bars indicate SEM. For each frequency, asterisks indicate significant difference ${ }^{*} P \leq 0.05$, ${ }^{* *} P \leq 0.01,{ }^{* * *} P \leq 0.001$, ANOVA with Tukey-Kramer post-test) from control mutant thresholds (red). $P$ values, specific test, test value, and degrees of freedom for all comparisons in this dataset are shown in Supplemental Table Comparison 2. dB, decibels; SPL, sound pressure level; kHz, kilohertz; BBN, broad-band noise; GA, Ush1c c.216GA littermate controls, AA, Ush1c c.216AA

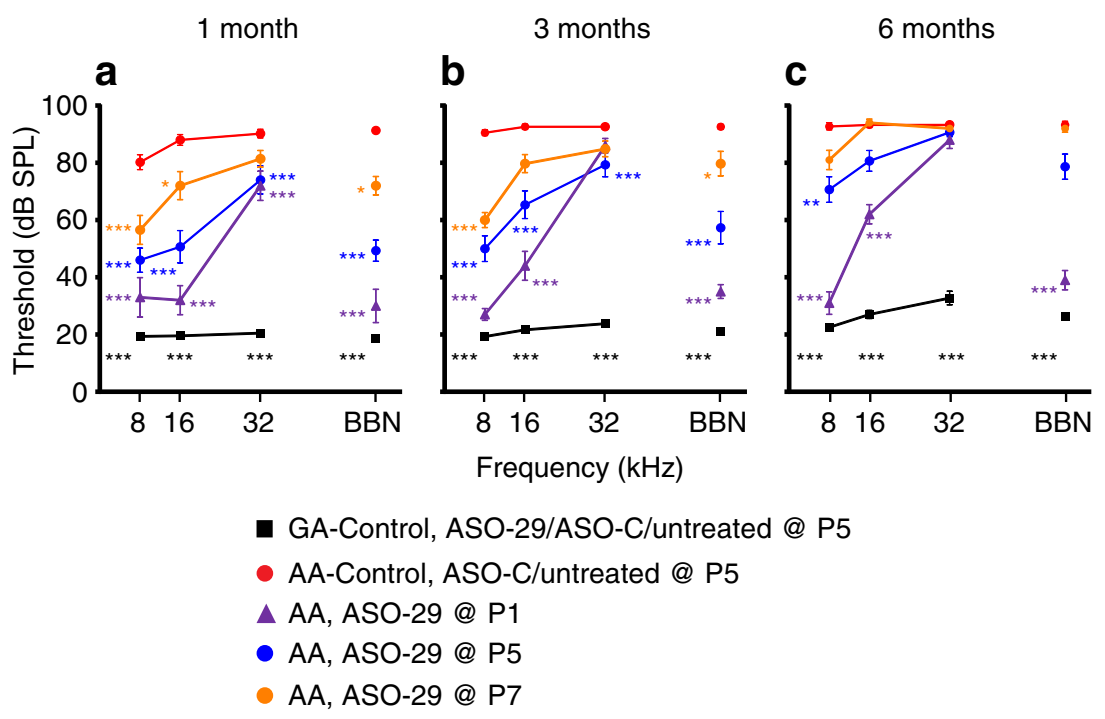

Fig. 5. Auditory evoked brainstem analysis in Ush1c mice treated with a single dose of ASOs. Average ABR thresholds (dB SPL) at 1 month (a), 3 months (b), and 6 months (c) of age to pure tones ranging from 8 to $32 \mathrm{kHz}$ or BBN from 216AA mice treated with $300 \mathrm{mg} / \mathrm{kg}$ of ASO-29 one time at P1 (purple line, $n=6,6$, and 6 at 1,3 , and 6 months of age, respectively), P5 (blue line, $n=9,9$, and 9 at 1,3 , and 6 months of age, respectively) or P7 (orange line, $n=7$, 7 and 6 at 1,3, and 6 months of age, respectively); 216AA mice treated with ASO-C or untreated (red line, $n=27,23$ and 11 at 1, 3 and 6 months of age); and 216GG/GA mice treated by IP injection with ASO-29, ASO-C, and untreated (black line, $n=31,28$, and
24 at 1,3 , and 6 months of age, respectively). ABR thresholds are reduced at some frequencies at all ages in 216AA mice treated with a single dose of ASOs in the first week of life. Error bars indicate SEM. For each frequency, asterisks indicate significant difference $\left({ }^{*} P \leq 0.05,{ }^{*} P \leq 0.01,{ }^{* * *} P \leq 0.001\right.$, ANOVA with Tukey-Kramer post-test) from control mutant thresholds (red). $P$ values, specific test, test value, and degrees of freedom for all comparisons in this dataset are shown in Supplemental Table Comparisons 3 and 4. dB, decibels; SPL, sound pressure level; $\mathrm{kHz}$, kilohertz; $\mathrm{BBN}$, broadband noise; GG/GA, Ush1c c.216GG/GA littermate controls, AA, Ush1c c.216AA 


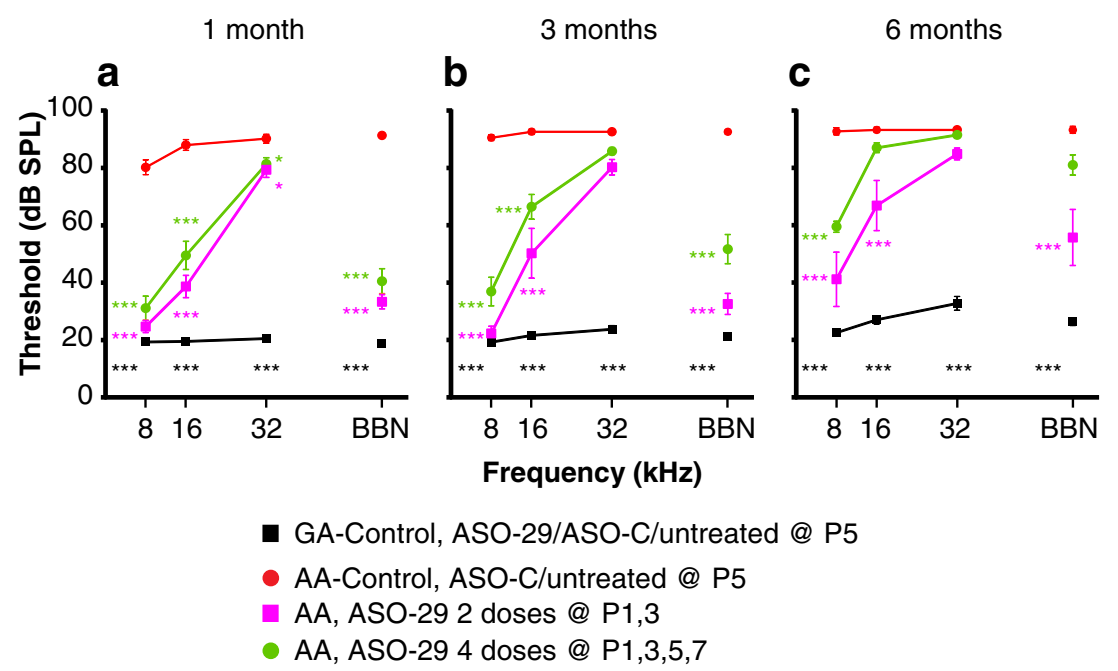

Fig. 6. Auditory evoked brainstem analysis in Ush1c mice treated with multiple doses of ASOs. Average ABR thresholds (dB SPL) at 1 month (a), 3 months (b), and 6 months (c) of age to pure tones ranging from 8 to $32 \mathrm{kHz}$ or $\mathrm{BBN}$ from 216AA mice treated with $300 \mathrm{mg} / \mathrm{kg}$ of ASO-29 twice at P1 and 3 (P1-3, pink line, $n=9,7$, and 7 at 1,3 and 6 months of age) or four times at $\mathrm{P} 1,3,5$, and 7 ( $\mathrm{P} 1-7$, green line, $n=16,13$, and 12 at 1,3 , and 6 months of age); 216AA mice treated with ASO-C or untreated (red line, $n=27,23$, and 11 at 1,3 , and 6 months of age, respectively); and $216 \mathrm{GG} / \mathrm{GA}$ mice treated by IP injection with ASO-29, ASO-C, and untreated (black line, $n=31,28$, and 24 at

low and mid frequencies compared with their normal hearing 216GA heterozygous littermates (Supplemental Table Comparison 3). For high-frequency stimuli (32 kHz), ABR thresholds in ASO-treated 216AA mice were significantly reduced compared with 216AA controls for all ASO treatments except in mice treated at P7 (Fig. 5a). When a single dose of ASOs was given as late as P7, low-mid-frequency hearing, but not highfrequency hearing, was rescued. At $8 \mathrm{kHz}, \mathrm{ABR}$ thresholds after a single ASO treatment at P1 were significantly different from treatment at $\mathrm{P} 7$, but not P5. At $16 \mathrm{kHz}, \mathrm{ABR}$ thresholds after a single ASO treatment at $\mathrm{P} 1,5$, or 7 were significantly different from each other, with P1 having the lowest thresholds among all three treatment ages. There was no significant difference in ABR thresholds between the three treatment ages at $32 \mathrm{kHz}$. Multiple ASO treatments in 216AA mice at $\mathrm{P} 1$ and 3 had the lowest ABR thresholds at $8 \mathrm{kHz}$ (24 dB SPL; Fig. 6a). However, there was no significant difference in thresholds between a single treatment at P1 (33 dB SPL; Fig. 5a) and two treatments at P1 and $3(25 \mathrm{~dB}$ SPL; Fig. 6a) at $8 \mathrm{kHz}$. Among the multiple treatment regimens (two doses versus four doses), there were no significant differences in $\mathrm{ABR}$ thresholds at 1 month of age for all the stimuli tested.

At 3 months of age, ABR thresholds in response to low-frequency stimulation $(8 \mathrm{kHz})$ remained significantly lower in 216AA mice for all ASO treatments
1,3 , and 6 months of age, respectively). ABR thresholds are reduced at some frequencies at all ages in 216AA mice treated with multiple doses of ASOs in the first week of life. Error bars indicate SEM. For each frequency, asterisks indicate significant difference $\left({ }^{*} P \leq 0.05,{ }^{* *} P \leq 0.01,{ }^{* * *} P \leq 0.001\right.$, ANOVA with Tukey-Kramer post-test) from control mutant thresholds (red). $P$ values for additional comparisons in this dataset shown in Supplemental Table Comparisons 3 and 4. Total number of treatments (doses) is indicated. $\mathrm{dB}$, decibels; $\mathrm{SPL}$, sound pressure level; kHz, kilohertz; BBN, broad-band noise; GG/GA, Ush1c c.216GG/GA littermate controls, AA, Ush1c c.216AA

compared with mutant controls (Figs. 5b and 6b). For mid-frequency $(16 \mathrm{kHz})$ and $\mathrm{BBN}$ stimuli, ABR thresholds remained significantly lower compared with 216AA control-treated mice for all ASO treatments except for P7. Additionally, ABR thresholds of P1- and P1, 3-treated 216AA mice were not significantly different for $8 \mathrm{kHz}$ and BBN stimulus $(\mathrm{P} 1,3)$ compared with heterozygous littermates. For the highfrequency $(32 \mathrm{kHz})$ stimulus, a single treatment at $\mathrm{P} 5$ and 2 treatments at P1, 3 had ABR thresholds that remained significantly reduced compared with 216AA controls.

There was no significant difference in ABR thresholds between 1- and 3-month-old ASO-treated 216AA mice for all frequencies and all treatments except at $16 \mathrm{kHz}$ in 216AA mice treated with four doses (P1, 3, 5, 7) (Figs. 5a, b and 6a, b). Remarkably, ABR thresholds in response to low-frequency stimulation $(8 \mathrm{kHz} 33,27$, and $31 \mathrm{~dB}$ SPL at 1,3 , and 6 months of age, respectively; Fig. 5) and BBN stimulus (30, 35, and $39 \mathrm{~dB}$ SPL at 1, 3, and 6 months of age, respectively; Fig. 5) in 216AA mice treated one time at P1 were stable until 6 months of age, remaining significantly lower compared with 216AA controls (Fig. $5 \mathrm{c}$ ). For all other ASO treatments and frequencies tested, ABR thresholds were elevated at 6 months of age (Figs. $5 \mathrm{c}$ and $6 \mathrm{c}$ ). This elevation notwithstanding, ABR thresholds in mice that underwent all treatment regimens remained significantly lower com- 
pared to control 216AA mice except those treated at P7. ABR thresholds in response to low-frequency stimulation $(8 \mathrm{kHz})$ were significantly lower compared with 216AA controls for a single ASO treatment at P1 or P5 and multiple treatments at P1, 3 or P1, 3, 5, 7 (Figs. 5c and 6c). For mid-frequency $(16 \mathrm{kHz})$ and BBN stimuli, ABR thresholds in mice treated at P1 and $\mathrm{P} 1,3$ remained significantly lower compared with 216AA control-treated mice. For the high-frequency $(32 \mathrm{kHz})$ stimulus, ABR thresholds were not significantly different in ASO-treated 216AA mice compared with 216AA controls. For single treatments, 6-month ABR thresholds were significantly lower at low-mid (8 and $16 \mathrm{kHz}$ ) frequency and BBN stimulus in 216AA mice treated at P1 compared to P5 and P7 (Supplemental Table Comparison 3). For multiple treatments, ABR thresholds were significantly lower at low-mid (8 and $16 \mathrm{kHz}$ ) frequency and BBN stimulus in 216AA mice treated with 2 doses at P1, 3 compared to 4 doses at $\mathrm{P} 1,3,5$, and 7 . ABR thresholds were not significantly different for low-frequency stimulation $(8 \mathrm{kHz})$ and BBN stimulus in P1-treated 216AA mice compared with 216GA heterozygous littermates. Although there was variance associated with stimulus frequency and duration of effect, these data demonstrate that all treatment regimens resulted in ABR threshold rescue.

\section{Correction of Ush1c c.216A Splicing in the Cochleae of ASO-Treated Mice}

To determine the effect of the number and timing of ASO-29 treatments on Ush1c c.216A splicing, Ush1c mRNA was isolated from cochlear tissue that was harvested from 6-month-old 216AA mice treated with ASOs once at $\mathrm{P} 1, \mathrm{P} 5$, or $\mathrm{P} 7$ or with two doses at $\mathrm{P} 1$ and $3(\mathrm{P} 1,3)$ or four doses at $\mathrm{P} 1,3,5$, and 7 (P1, 3, 5, 7). RT-PCR analysis of cochlear mRNA revealed that a small percent of the total Ush1c c.216A mRNA was correctly spliced (Fig. 7). The amount of correctly spliced mRNA was highest in the cochleae from mice treated with multiple doses of the ASO. The relative abundance of correctly spliced mRNA was not significantly different among the treatment regimens, suggesting that the delivery of the ASO to the cochlea is similar at the different treatment ages and results in a similar correction of splicing (Fig. 7). Overall, our results suggest that treatment prior to $\mathrm{P} 5$ is critical for the rescue of $\mathrm{OHC}$ function likely due to a temporal requirement for harmonin rather than a result of temporal differences in ASO delivery.

\section{Localization of ASO-29 in Ush1c Cochlear Hair Cells}

To determine whether intraperitoneal ASO treatment results in localization of ASO to both HC populations,

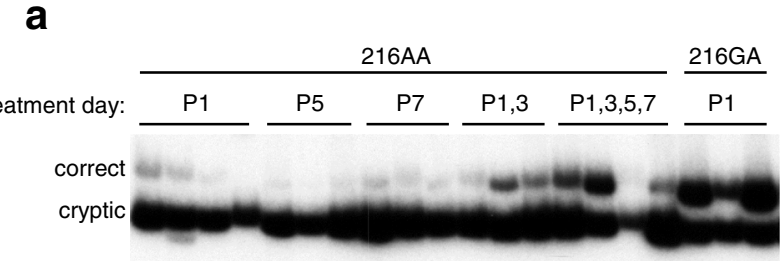

skipped

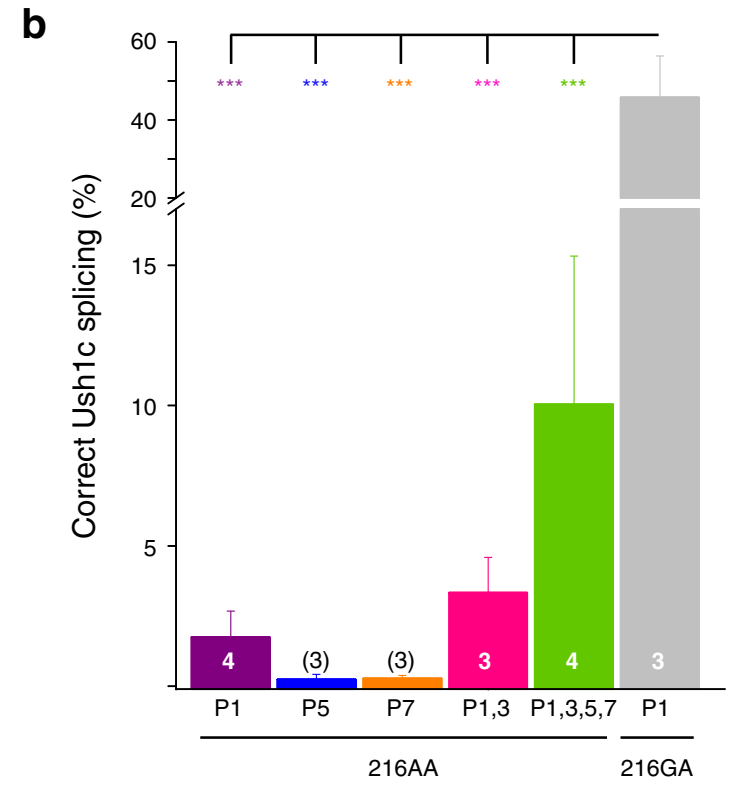

Fig. 7. ASO-mediated correction of Ush1c c.216A pre-mRNA splicing 6 months post-injection. a RT-PCR analysis of cochlear RNA isolated from 6-month-old mice treated with $300 \mathrm{mg} / \mathrm{kg}$ of ASO-29 at indicated post-natal day(s). Spliced products are labeled. b Quantitation of PCR products shown in a. Asterisks indicate significant difference $\left({ }^{* * *} P \leq 0.001\right.$, one-way ANOVA, Tukey's multiple comparison test)

we performed immunofluorescence analysis of the organs of Corti of treated Ush1c mice using an antibody that specifically recognizes the ASO. 216AA mice were treated with ASO-29 or saline at P1 or P5 and tissues harvested at P12 and P30. At P12, ASO (red puncta) was detected in 216AA mutant IHCs and OHCs at the apex, mid, and basal regions of the cochlea (Fig. 8). ASO-29 was still abundant in both IHCs and OHCs of treated mice at 1 month of age (Fig. 9a, b). ASO-29 was also observed surrounding the HCs in a pattern suggesting localization within support cells. Saline-treated control littermates displayed little or no red puncta, demonstrating the specificity of the antibody for the ASO (Fig. 9c). These results demonstrate the presence of ASO-29 in the hair cells and indicate that there is similar localization of ASO to HCs in P12 and P30 mice that were treated at P1 or P5 with ASO-29. 


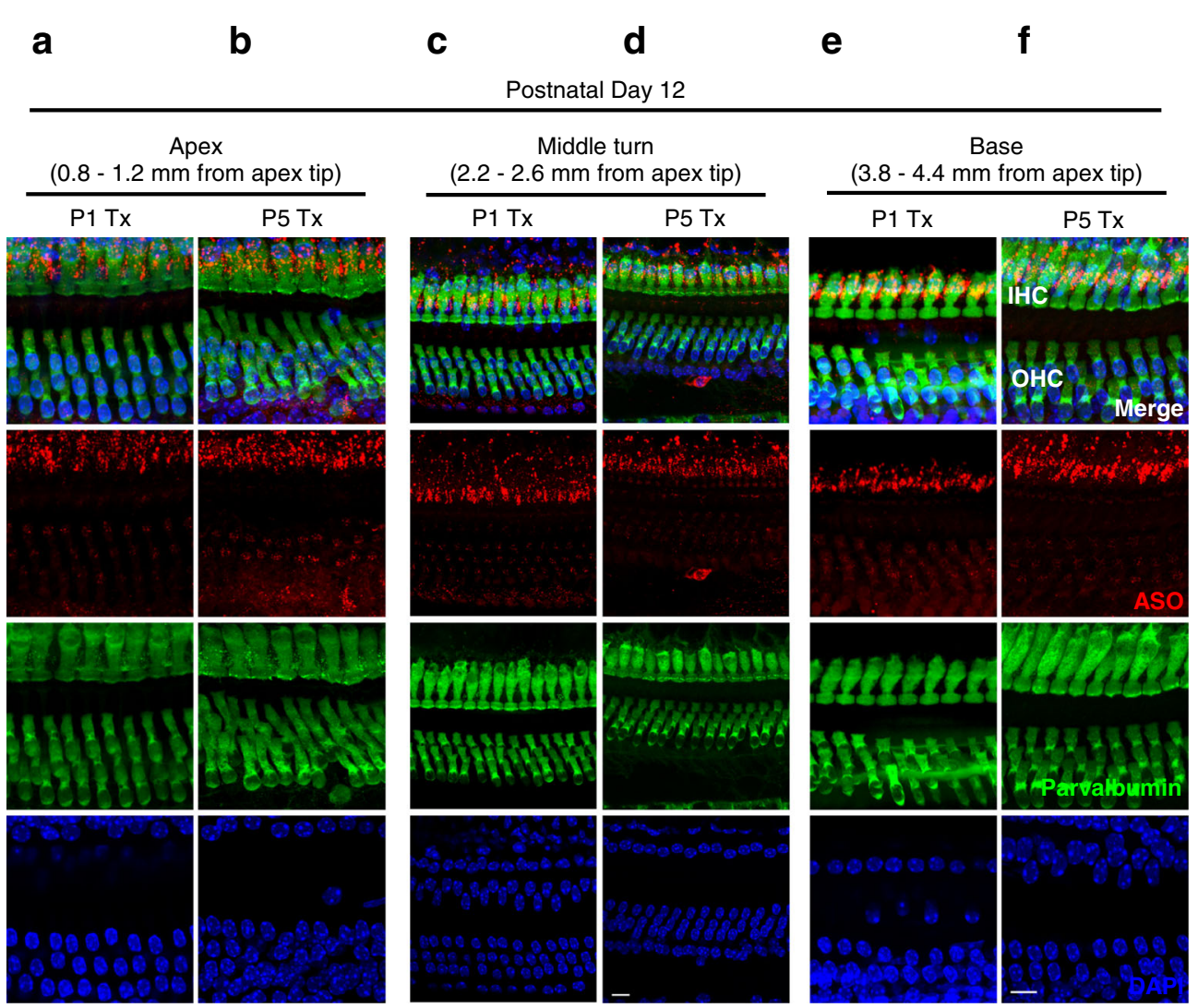

Fig. 8. Localization of ASOs in auditory hair cells at P12 after systemic treatment in Ush1c mice. Immunofluorescent labeling of ASO-29 (red) in HCs (green) at the $\mathbf{a}, \mathbf{b}$ apex, $\mathbf{c}, \mathbf{d}$ middle turn, and $\mathbf{e}, \mathbf{f}$ base at P12 after ASO treatment at P1 or P5. Distance from the apex tip is indicated. Scale bars indicate $10 \mu \mathrm{m}$. IHC, inner hair cell; OHC, outer hair cell; ASO, antisense oligonucleotide

\section{DISCUSSION}

In this study, we have identified a critical time at which treatment must occur in order to rescue IHC and OHC function in a mouse model of Usher syndrome using ASOs that correct Ush1c c.216A gene expression. Our previous work with Ush1c c.216G $>\mathrm{A}$ (216AA) mice demonstrated that although mutant mice exhibit little or no hearing and abnormal balance during locomotion (Lentz et al. 2007), ASO29 treatment can rescue auditory function and eliminate circling behavior (Lentz et al. 2013). In particular, when compared with control- and untreated-mutant ABRs, measures of auditory sensitivity demonstrated a threshold reduction of $\sim 44 \mathrm{~dB}$ in ASO-treated mutant mice. However, it was yet to be determined if this increase in sensitivity was due to improved IHC and OHC function or limited to IHCs alone. Indeed, the rescued ABR thresholds remained above those of wild-type controls, raising the possibility that therapeutic effects of the ASO may be limited to IHC mechanisms, unaided by the active process. Thus, here we utilize a functional measure of the active process, DPOAE, to quantify the effect of ASO treatment on OHC function.
Our results show that 216GA heterozygous mice, which have ABR thresholds similar to wild-type mice, also exhibit typical DPOAEs with measurable distortion products in response to two tones of a given frequency and sound pressure level. In contrast, 1month-old homozygous 216AA mutant mice exhibit profoundly attenuated ABRs and have little or no DPOAEs. A single systemic ASO treatment at P5 rescued low- and mid-frequency ABRs but did not rescue DPOAEs suggesting that ASO-29 can rescue IHC, but not OHC function. However, treatment with ASO-29 earlier than P5, including a single dose at P1 or multiple doses beginning at P1, significantly improved both ABRs and DPOAEs, suggesting that OHC function can be rescued by ASO-29. Although ABR and DPOAE thresholds were lower with two doses at P1 and 3 compared to a single dose at P1, there was no significant difference between them, suggesting little added benefit from an additional dose at P3. Interestingly, four doses of ASO-29 at P1, 3,5 , and 7 were not as effective at rescuing DPOAEs or ABRs compared to a single treatment at $\mathrm{P} 1$ or two doses at P1 and P3 (Figs. 1, 3, and 4) despite a trend towards a higher level of splicing correction (Fig. 7). We hypothesize that the most important dosing is at 
a

b

Apex-mid at P30 (1.8 - $2.2 \mathrm{~mm}$ from apex tip)
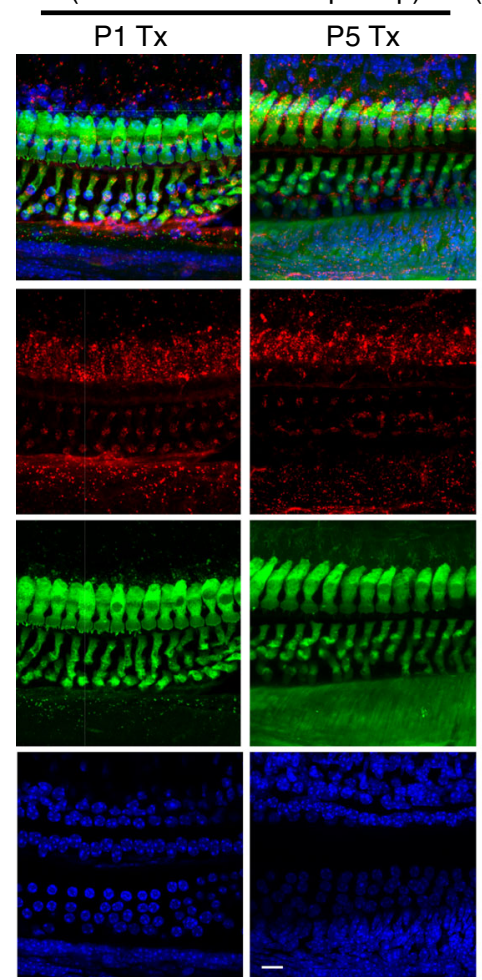

C

Saline at $\mathrm{P} 12$

(1.8 - $2.2 \mathrm{~mm}$ from apex tip)
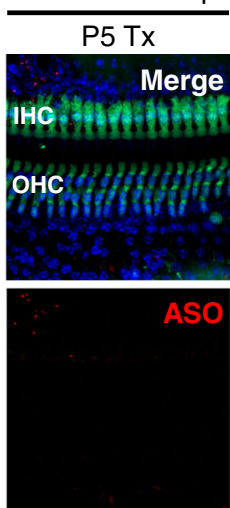

Parvalbumin
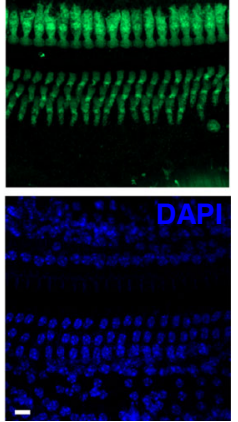

Fig. 9. Localization of ASOs in auditory hair cells at P30 after systemic treatment in Ush1c mice. Immunofluorescent labeling of ASO-29 (red) in HCs (green) at the $\mathbf{a}, \mathbf{b}$ apex-mid turn at P30 after ASO treatment at P1 (a) or P5 (b). c Immunofluorescent image at the apex-middle turn of P5 vehicle-treated (saline), control littermate 1 week after P5 ASO treatment (P12). Scale bars indicate $10 \mu \mathrm{m}$. IHC, inner hair cell; OHC, outer hair cell; ASO, antisense oligonucleotide

P1 and that harmonin expression between P1 and P3 is critical for the HC functions that we measured. The explanation for the lack of increased efficacy with this treatment regimen is not clear. It is possible that repeated IP dosing early in life has specific or nonspecific toxic effects in the animal that affect IHC and OHC function. Overall, our results demonstrate the importance of early treatment for rescue of $\mathrm{OHC}$ function, which is consistent with a recent report that DPOAE thresholds could be rescued in 216AA mice following delivery of wild-type Ush1c to the inner ear in P1 pups using an adeno-associated viral vector (Pan et al. 2017).

It is possible that the lack of rescue of the OHC active process when ASO is delivered at $\mathrm{P} 5$ is a result of differences in the extent to which ASOs reach IHCs and OHCs. However, immunofluorescent analysis of ASO distribution in the cochlea $\sim 1$ week after treatment indicates that ASO is present in both IHCs and OHCs, though apparently more abundant in
IHCs (Fig. 8). By 1 month of age, approximately 3.5 weeks after treatment, when hearing assessment was performed, ASO was present in both IHCs and OHCs in areas that correspond to low- and midfrequency hearing (Fig. 9). The morphological data notwithstanding, the quantity of ASO reaching the OHCs and the timing of ASO-29 treatment may be expected to vary between hair cell types as their precursor cells and developmental times vary (Ruben 1967; Rubel 1978; Pirvola et al. 1991; Lim and Rueda 1992; Muller and Littlewood-Evans 2001; Liberman et al. 2002; Okoruwa et al. 2008; Ahmed et al. 2012; Burns et al. 2012). Furthermore, exposure within cell types may vary with time. Indeed, development of OHC transduction currents proceed basal to apical (P0-P2), making the timing of the ASO therapy at P5 more closely synchronized to OHC development in low-frequency regions than high-frequency basal turns (Waguespack et al. 2007). In either case, treatment with ASOs at P5 is likely subsequent to much of the OHC transduction development, suggesting that the failure of $\mathrm{OHC}$ rescue could be overcome with earlier ASO delivery.

In addition to their different morphologies, functions and development, vestibular hair cells, IHCs, and OHCs vary in their response to different genetic deletions (Friedman et al. 2007; Dror and Avraham 2010; Fritzsch et al. 2013). The results here, showing a failure of ASO-29 to rescue OHC function at P5 (but success in IHC and vestibular function as previously reported Lentz et al. 2013 and Vijayakumar et al. 2017), suggest that the function of harmonin, the amount expressed, and/or the cells sensitivity to mutant protein levels may be relevant to these distinguishing characteristics. Thus, not only do the data here create a framework of understanding both the disease and therapeutic mechanisms, but they also contribute to our knowledge of the differences in the underlying proteomic mechanisms differentiating these cell types.

With respect to heritable deafness mutations, evidence in humans also suggests differences in IHC and OHC mechanisms. Humans with Usher syndrome and other forms of hearing loss present with hearing deficits consistent with IHC and OHC functional loss (Shinkawa and Nadol 1986; Cohn et al. 1999; Wagenaar et al. 2000). Interestingly, while pure tone ABR thresholds are similar, differences in OAEs between carriers and non-carriers of mutations that cause several different types of hearing impairment are observed, including carriers of Usher syndrome type $1 \mathrm{C}$, some carriers of the $35 \mathrm{delG}$ mutation in Connexin 26 (Cx26), Ashkenazi Jewish carriers of the 167delT mutation in Cx26, DFNA11, and autosomal dominant non-syndromic hearing impairment caused by a mutation in the myosin VIIA gene (Morell and 
Friedman 1999; Engel-Yeger et al. 2002; Hood et al. 2002; Tamagawa et al. 2002; Engel-Yeger et al. 2003; Franze et al. 2005). Thus, our data are consistent with the phenotypes of these diseases, as our data also suggest different underlying mechanisms of the mutation in IHCs and OHCs.

The current study establishes the critical time in the development of hearing at which treatment must occur in order to correct both IHC and OHC dysfunction in Usher syndrome type 1C. We have established that ASOs are an effective drug platform to achieve hearing rescue for a human form of congenital deafness in mice. ASOs have emerged as a powerful therapeutic for a number of different diseases and conditions in humans, some of which have been approved for clinical use (Gryn and Hegele, 2015; Havens and Hastings, 2016; Finkel et al. 2016). From a therapeutic perspective for type 1 Usher syndrome, ASOmediated treatment of hearing would likely require a very early intervention point in humans, where hair cell development occurs early in gestation in utero. We have recently reported on the ability of ASOs to access the cochleae of mice exposed to the molecule via injection into the amniotic cavity (Depreux et al. 2016). This result suggests that early treatment with ASOs in utero is feasible in mice and could be utilized as a means to deliver a potential ASO drug during the critical period for hearing development.

\section{FUNDING INFORMATION}

We gratefully acknowledge support from the National Institutes of Health (1R01DC012596 (MLH), 1 U54 GM104940 (JJL), P30 GM104940 (JJL)), Foundation Fighting Blindness (JJL, MLH), Eye on Jacob Foundation (JJL), Ush One See (JJL), Usher 2020 Foundation (JJL), Hearing Health Foundation (MLH), Midwest Eye-Banks (MLH), Capita Foundation (MLH), and the National Organization for Hearing Research (MLH).

\section{AUTHOR CONTRIBUTIONS}

The project was conceived of by J.J.L. and M.L.H.

ABR and DPOAE experimental setup was developed and designed by A.P., H.E.F., and J.J.L.. Immunohistochemistry experimental setup was developed and designed by J.J.L. Splicing experimental setup was developed and designed by F.F.D. and M.L.H.

A.P. performed ABR and DPOAE experiments and analyzed data. J.J.L. performed immunohistochemistry experiments. F.F.D. and F.M.J. performed splicing experiments and analyzed data.
A.P., H.E.F., F.F.D., F.R., M.L.H., and J.J.L. interpreted the results. A.P., H.E.F., M.L.H and J.J.L. wrote the paper.

\section{COMPLIANCE WITH ETHICAL STANDARDS}

All procedures met the NIH guidelines for care and use of laboratory animals and were approved by the Animal Care and Use Committee at LSUHSC.

Competing Interests F.R. is an employee of Ionis Pharmaceuticals. M.L.H. receives funding from Ionis Pharmaceuticals. A.P., H.E.F., and J.J.L declare that they have no competing interests.

Open Access This article is distributed under the terms of the Creative Commons Attribution 4.0 International License (http://creativecommons.org/licenses/by/4.0/), which permits unrestricted use, distribution, and reproduction in any medium, provided you give appropriate credit to the original author(s) and the source, provide a link to the Creative Commons license, and indicate if changes were made.

\section{REFERENCES}

Ahmed M, Wong EYM, Sun JB, Xu JS, Wang F, Xu PX (2012) EyalSix1 interaction is sufficient to induce hair cell fate in the cochlea by activating Atoh1 expression in cooperation with Sox2. Dev Cell 22:377-390

Bitner-Glindzicz M, Lindley KJ, Rutland P, Blaydon D, Smith VV, Milla PJ, Hussain K, Furth-Lavi J, Cosgrove Ke, Shepherd RM, Barnes PD, O'Brien Re, Farndon PA, Sowden J, Liu XZ, Scanlan MJ, Malcolm S, Dunne MJ, Aynsley-Green A, Glaser B (2000) A recessive contiguous gene deletion causing infantile hyperinsulinism, enteropathy and deafness identifies the Usher type 1C gene. Nat Genet 26:56-60

Boeda B, El-Amraoui A, Bahloul A, Goodyear R, Daviet L, Blanchard S, Perfettini I, Fath KR, Shorte S, Reiners J, Houdusse A, Legrain P, Wolfrum U, Richardson G, Petit C (2002) Myosin VIIa, harmonin and cadherin 23, three Usher I gene products that cooperate to shape the sensory hair cell bundle. EMBO J 21:6689-6699

Burns JC, On D, Baker W, Collado MS, Corwin JT (2012) Over half the hair cells in the mouse utricle first appear after birth, with significant numbers originating from early postnatal mitotic production in peripheral and striolar growth zones. Jaro-J Assoc Res Otolaryngol 13:609-627

Clark W, Clark C, Moody D, Stebbins W (1974) Noise-induced hearing loss in the chinchilla, as determined by a positivereinforcement technique. J Acoust Soc Am 56:1202-1209

Cohn ES, Kelley PM, Fowler TW, Gorga MP, Lefkowitz DM, Kuehn HJ, Schaefer GB, Gobar LS, Hahn FJ, Harris DJ, Kimberling WJ (1999) Clinical studies of families with hearing loss attributable to mutations in the connexin 26 gene (GJB2/DFNB1). Pediatrics 103:546-550

Dallos P, Wu XD, Cheatham MA, Gao JG, Zheng J, Anderson CT, Jia SP, Wang X, Cheng WHY, Sengupta S, He DZZ, Zuo J (2008) Prestin-based outer hair cell motility is necessary for mammalian cochlear amplification. Neuron 58:333-339 
Depreux FF, Wang L, Jiang H, Jodelka FM, Rosencrans RF, Rigo R, Lentz JJ, Brigande JV, Hastings ML (2016) Antisense oligonucleotides delivered to the amniotic cavity in utero modulate gene expression in the postnatal mouse. Nucleic Acids Res 44(20):9519-9529

Dror AA, Avraham KB (2010) Hearing impairment: a panoply of genes and functions. Neuron 68:293-308

Engel-Yeger B, Zaaroura S, Zlotogora J, Shalev S, Hujeirat Y, Carrasquillo M, Barges S, Pratt H (2002) The effects of a connexin 26, mutation-35delG-on oto-acoustic emissions and brainstem evoked potentials: homozygotes and carriers. Hear Res 163:93-100

Engel-Yeger B, Zahroura S, Zlotogora J, Shalev S, Hujeirat Y, Carrasquillo M, Saleh B, Pratt H (2003) Otoacoustic emissions and brainstem evoked potentials in compound carriers of connexin 26 mutations. Hear Res 175:140-151

Finkel RS, Chiriboga CA, Vajsar J, Day JW, Montes J, De Vivo DC, Yamashita M, Rigo F, Hung G, Schnieder E, Norris DA, Xia S, Bennett CF, Bishop KM (2016) Treatment of infantile-onset spinal muscular atrophy with nusinersen: a phase 2, open-label, dose-escalation study. Lancet 388(10063):3017-3026

Franze A, Caravelli A, Di Leva F, Marciano E, Auletta G, D'Aulos F, Saulino C, Esposito L, Carella M, Gasparini P (2005) Audiometric evaluation of carriers of the connexin 26 mutation 35delG. Eur Arch Otorhinolaryngol 262:921-924

Friedman LM, Dror AA, Avraham KB (2007) Mouse models to study inner ear development and hereditary hearing loss. Int J Dev Biol 51:609-631

Fritzsch B, Pan N, Jahan I, Duncan JS, Kopecky BJ, Elliott KL, Kersigo J, Yang T (2013) Evolution and development of the tetrapod auditory system: an organ of corti-centric perspective. Evol Dev 15:63-79

Gold T (1948) Hearing. 2. The physical basis of the action of the cochlea. Proc R Soc Ser B-Biol Sci 135:492-498

Grillet N, Xiong W, Reynolds A, Kazmierczak P, Sato T, Lillo C, Dumont RA, Hintermann E, Sczaniecka A, Schwander M, Williams D, Kachar B, Gillespie PG, Muller U (2009) Harmonin mutations cause mechanotransduction defects in cochlear hair cells. Neuron 62:375-387

Gryn SE, Hegele RA (2015) Novel therapeutics in hypertriglyceridemia. Curr Opin Lipidol 26(6):484-491

Havens MA, Hastings ML (2016) Splice-switching antisense oligonucleotides as therapeutic drugs. Nucleic Acids Res 44(14):65496563

Harris F, L-M BL, Stagner B, Coats A, Martin G (1989) Acoustic distortion products in humans: systematic changes in amplitudes as a function of $\mathrm{f} 2 / \mathrm{f1}$ ratio. J Acoust Soc Am 85:220-229

Hood LJ, Tedesco S, Brashears S, Rose K, Keats BJ, Berlin CI (2002) Auditory characteristics in carriers of genes related to Usher syndrome. In: 2002 ARO

Horner KC, Lenoir M, Bock GR (1985) Distortion product otoacoustic emissions in hearing-impaired mutant mice. J Acoust Soc Am 78:1603-1611

Keats BJ, Corey DP (1999) The usher syndromes. Am J Med Genet 89:158-166

KemP DT (1978) Stimulated acoustic emissions from within the human auditory system. J Acoust Soc Am 64:1386-1391

KEMP DT (1979) Evidence of mechanical nonlinearity and frequency selective wave amplification in the cochlea. Arch Otorhinolaryngol 224:37-45

Kramer CY (1956) Extension of multiple range tests to group means with unequal numbers of replications. Biometrics 12:307-310

Lefevre G, Michel V, Weil D, Lepelletier L, Bizard E, Wolfrum U, HaRdelin JP, Petit C (2008) A core cochlear phenotype in USH1 mouse mutants implicates fibrous links of the hair bundle in its cohesion, orientation and differential growth. Development 135:1427-1437
Lentz J, Pan F, Ng SS, Deininger P, Keats B (2007) Ush1c216A knock-in mouse survives Katrina. Mutat Res 616:139-144

Lentz J, Savas S, Ng SS, Athas G, Deininger P, Keats B (2005) The USHIC 216G $\rightarrow>$ A SPLICE-SITE MUTATION RESULTS IN A 35-BASE-PAIR DELETION. Hum GENET 116:225-227

Lentz JJ, Jodelka FM, Hinrich AJ, McCafrrey Ke, Farris He, Spalitta MJ, Bazan NG, Duelli DM, Rigo F, Hastings ML (2013) Rescue of hearing and vestibular function by antisense oligonucleotides in a mouse model of human deafness. Nat Med 19:345-350

Lentz JJ, Gordon WC, Farris He, MacDonald GH, Cunningham DE, Robbins CA, Tempel bl, Bazan NG, Rubel EW, Oesterle EC, KEATS BJ (2010) Deafness and retinal degeneration in a novel USH1C knock-in mouse model. Dev Neurobiol 70:253-267

Liberman MC, Gao JG, He DZZ, Wu XD, Jia SP, Zuo J (2002) Prestin is required for electromotility of the outer hair cell and for the cochlear amplifier. Nature 419:300-304

Lim D, Rueda J (1992) Structural development of the cochlea. In: Romand R (ed) Development of aUditory and vestibular sYSTEMS, 1St edn. ElseVier, AMsterdam, PP 33-58

Martin G, Stagner B, Lonsbury-Martin B (2006) Assessment of COCHLEAR FUNCTION IN MICE: DISTORTION-PRODUCT OTOACOUSTIC emissions. Curr Protoc Neurosci. https://Doi.org/10.1002/ 0471142301.ns0821cs34

Mathur P, Yang J (2015) Usher syndrome: hearing loss, retinal degeneration and associated abnormalities. Biochim Biophys Acta 1852:406-420

Miluiken GA, Johnson DE (1984) Analysis of messy data. Volume I: designed experiments. Van Nostrad Reinhold Company NY, pp. 473

Moody D, Stebbins W, Hawkins JJ, Johnsson L (1978) Hearing loss and cochlear pathology in the monkey (Macaca) following exposure to high levels of noise. Arch Otorhinolaryngol 220:47-72

Morell RJ, Friedman TB (1999) Deafness and mutations in the CONNEXin 26 Gene-The Authors Reply. N Engl J Med 340:12881288

Muller U, Littlewood-Evans A (2001) Mechanisms that regulate mechanosensory hair cell differentiation. Trends Cell Biol 11:334-342

Okoruwa Oe, Weston MD, Sanjeevi DC, Millemon AR, Fritzsch B, Hallworth R, Beisel KW (2008) Evolutionary insights into the unique electromotility motor of mammalian outer hair cells. Evol Dev 10:300-315

Pan B, Askew C, Galvin A, Heman-Ackah S, Asai Y, Indzhykulian AA, Jodelka FM, Hastings ML, Lentz JJ, Vandenberghe LH, Holt JR, GeLEOC GS (2017) Nat biotech epub ahead of print doi:https:// doi.org/10.1038/nbt.3081

Pirvola U, Lehtonen E, Ylikoski J (1991) Spatiotemporal development of cochlear innervation and hair cell-differentiation in the rat. Hear Res 52:345-355

Rubel EW (1978) Ontogeny of structure and function in the vertebrate auditory system. In: Handbook of sensory physiology, Vol. IX, development of sensory systems (Jacobson M, ed), pp 135-237: Springer-Verlag

Ruben RJ (1967) Development of the inner ear of the mouse: a radioautographic study of terminal mitoses. Acta Otolaryngol Suppl 220:221-244

Ryan A, Dallos P (1975) Effect of absence of cochlear outer hair cells on behavioural auditory threshold. Nature 253:44-46

Schrott A, Puel JL, Rebillard G (1991) Cochlear origin of 2f1-f2 distortion products assessed by using 2 types of mutant mice. Hear Res 52:245-253

Shinkawa H, Nadol JBJ (1986) Histopathology of the inNer EAR in USHER'S SYNDROME AS OBSERVED BY LIGHT AND ELECTRON MICROSCOPY. AnN Otol Rhinol LaRingol 95(3): 313-318

Smith DW, Moody DB, Stebbins WC, Norat MA (1987) Effects of outer hair cell loss on the frequency selectivity of the patas monkey auditory system. Hear Res 29:125-138 
Stebbins W, Miller J, Johnsson L, Hawkins JJ (1969) Ototoxic hearing loss and cochlear pathology in the monkey. Ann Otol Rhinol Laryngol 78:1007-1025

Stebbins WC, Hawkins JE JR, Johnson LG, Moody DB (1979) Hearing thresholds with outer and inner hair cell loss. Am J Otolaryngol $1: 15-27$

Tamagawa Y, Ishikawa K, Ishikawa K, Ishida T, Kitamura K, Makino S, Tsuru T, IChimura K (2002) Phenotype of DFNA11: a nonsyndromic hearing loss caused by a myosin VIIA mutation. Laryngoscope 112:292-297

Verpy E, Leibovici M, Zwaenepoel I, Liu XZ, Gal A, Salem N, Mansour A, Blanchard S, Kobayashi I, Keats BJ, Slim R, Petit C (2000) A defect in harmonin, a PDZ domain-containing protein expressed in the inner ear sensory hair cells, underlies Usher syndrome type 1C. Nat Genet 26:51-55
Vijayakumar S, Depreux F, Jodelka FM, Lentz JJ, Rigo F, Jones TA, HAstings ML (2017) Rescue of peripheral vestibular function in Usher syndrome mice using a splice-switching antisense oligonucleotide. Hum Mol Genet. https://doi.org/10.1093/hmg/ ddx234

Wagenaar M, Schuknecht H, Nadol J Jr, Benraad-Van Rens M, PiekeDahl S, Kimberling W, Cremers C (2000) Histopathologic features of the temporal bone in usher syndrome type I. Arch Otolaryngol Head Neck Surg 126:1018-1023

Waguespack J, Salles FT, Kachar B, Ricci AJ (2007) Stepwise morphological and functional maturation of mechanotransduction in rat outer hair cells. J Neurosci 27:13890-13902

Zheng J, Shen WX, He DZZ, Kevin BL, Madison LD, Dallos P (2000) Prestin is the motor protein of cochlear outer hair cells. Nature 405:149-155 